\title{
A behavioural intervention improved cognitive function and depression in elderly people in residential homes
}

Proctor R, Burns A, Stratton Powell H, et al. Behavioural management in nursing and residential homes: a randomised controlled trial. Lancet 1999 Jul 3;354:26-9.

QUESTION: In elderly people living in residential and nursing homes, can a behavioural intervention by a geriatric mental health outreach team improve cognitive function, depression, behavioural problems, and functional disability?

\section{Design}

Randomised (allocation concealed), blinded (patients), controlled trial with 6 months of follow up.

\section{Setting}

10 residential homes and 2 nursing homes in Manchester, UK.

\section{Patients}

120 elderly people (10 per home, mean age 82 y, $82 \%$ women) who lived in residential or nursing homes and whom staff identified as being difficult to manage. $88 \%$ completed the study.

\section{Intervention}

Residential or nursing homes were matched by size and accreditation status. 1 home in each of the 6 pairs was randomised to the intervention and the other to a control group. In the intervention group, staff attended seven 1 hour seminars on topics that they had identified as important (eg, management of aggression, screaming). A mental health nurse also visited the homes weekly to help staff to develop care planning skills.

\section{Main outcome measures}

Cognitive function and depressive symptoms (automatic geriatric examination for computer-assisted taxonomy, score range 1 and $2=$ subclinical to $5=$ most severe), behavioural problems (Crichton Royal Behaviour Rating Scale, score range $0=$ no problems to $38=$ severe problems), and functional disability (Barthel activity of daily living index, score range $0=$ dependent to $20=$ independent).

\section{Main results}

After adjustment for baseline variables, residents in the intervention group had improved scores in cognitive function $(p=0.002)$ and depression $(p=0.004)$ but not in behavioural problems or functional disability compared with no intervention (table).

\section{Conclusion}

In elderly people living in residential or nursing homes, a behavioural intervention by a geriatric mental health outreach team improved cognitive function and depression but not behavioural problems or functional disability.

\section{COMMENTARY}

Research on behavioural interventions provides evidence that controlled behaviour management techniques can improve many of the psychiatric, behavioural, and physiological problems of the elderly. ${ }^{12}$ This study by Proctor et al is timely given the current emphasis on community based care and the massive growth of the elderly population in today's society.

The results are relevant to care providers of elderly people who live in residential or nursing homes. Investigators frequently cite the need to develop and provide on-site training programmes for nurses on the use of behavioural techniques. ${ }^{34}$ In this study, staff education was supplemented with weekly visits by a mental health nurse, who provided advice and support; the nurse was able to reinforce the knowledge obtained in the seminar and serve as a mentor to change nursing care practices. We must keep in mind, however, that follow up was only 6 months, and we do not know if the intervention had a long term effect after withdrawal of the intervention.

It is difficult to know why only depression and organic functioning were significantly changed in this study. The sample size may have been too small to detect significant effects on function and behaviour. Little information was provided on the education programme and the specific types of consultation services. Future studies should assess the fit between specific aspects of the intervention (eg, education topics and specific types of consultation services) and patient outcomes.

Behavioural interventions such as this have the potential to improve not only the quality of care delivered in residential homes but also the job satisfaction of nurses.

Connie S Wilkinson, RN, PhD Program Director, Staff development Southern Arizona VA Health Care System Tucson, Arizona, USA

abstract appears in abstract appears in Evidence-Based Mental Health.
Behavioural intervention by a geriatric mental health team v no intervention for elderly people in residential or nursing homes

\begin{tabular}{lccc}
\multirow{2}{*}{$\begin{array}{l}\text { Outcomes at } \\
6 \text { months }\end{array}$} & \multicolumn{2}{l}{ Mean score $\mathbf{( 9 5 \% \mathbf { C l } )}$} & $\begin{array}{l}\text { Adjusted mean score } \\
\text { difference }(\mathbf{C l})^{*}\end{array}$ \\
\cline { 2 - 4 } & Intervention & Control & $-0.7(-1.1$ to -0.2$)$ \\
\hline Cognitive function & $2.4(1.5$ to 3.2$)$ & $3.0(2.6$ to 3.5$)$ & $-0.5(-0.8$ to -0.1$)$ \\
\hline Depression & $0.5(0.3$ to 0.8$)$ & $0.9(0.6$ to 1.3$)$ & $-0.7(-3.0$ to 1.6$) \dagger$ \\
\hline Behaviour & $13.2(7.6$ to 18.8$)$ & $15.3(12.6$ to 18.1$)$ & $0.9(-0.8$ to 2.7$) \dagger$ \\
\hline Functional disability & $13.2(9.5$ to 16.9$)$ & $11.0(9.0$ to 13.0$)$ & 0 \\
\hline
\end{tabular}

*Mean differences favour the intervention group and are adjusted for sex, age, and baseline scores. $†$ Not significant. 